\title{
Extra Virgin olive oil mitigates hematotoxicity induced by acrylamide and oxidative damage in adult rats
}

\author{
Imen Ghorbel $^{1 *}$, Mariem Chaabane ${ }^{1}$, Awatef Elwej ${ }^{1}$, Choumous Kallel ${ }^{2}$, Naziha Grati Kamoun ${ }^{3}$, Najiba Zeghal ${ }^{1}$ \\ ${ }^{1}$ Animal Physiology Laboratory, Sfax Faculty of Sciences, University of Sfax, 3000 Sfax, BP 1171, Tunisia \\ ${ }^{2}$ Hematolology Laboratory, CHU Habib Bourguiba, University of Sfax, 3029 Sfax, Tunisia \\ ${ }^{3}$ Technology and Quality Research Unit, Olive Tree Institute, BP 1087,University of Sfax, 3000 Sfax, Tunisia
}

Received: Mar3, 2017, Revised: Apr4, 2017, Accepted: Apr20, 2017

\begin{abstract}
Acrylamide (ACR) is a dietary contaminant derived from a wide range of foods through the Maillard-reaction during the cooking process. The present study focused on the hematotoxic effects of ACR and the protective efficacy of Extra Virgin olive oil (EVOO) in alleviating hematotoxicity and oxidative stress in erythrocytes of adult rats. Rats were divided into four groups of six each: group 1, serving as negative controls, received distilled water; group 2 received by gavage ACR at a dose of $40 \mathrm{mg} / \mathrm{kg}$ body weight; group 3 received by gavage ACR supplemented with EVOO (300 $\mu \mathrm{L})$; group 4,serving as positive controls, received only EVOO by gavage. All groups were sacrificed after three weeks. Acrylamide induced a significant increase in white blood cells (WBC), erythrocyte osmotic fragility (OF) and a decrease in red blood cells (RBC), hemoglobin (Hb) and hematocrit $(\mathrm{Ht})$. While mean corpuscular volume $(\mathrm{MCV})$, mean corpuscular hemoglobin $(\mathrm{MCH})$ and $\mathrm{MCH}$ concentration $(\mathrm{MCHC})$ remained unchanged. Furthermore, exposure of rats to ACR induced erythrocytes oxidative stress with an increase of malondialdehyde, hydrogen peroxide, and protein carbonyls levels. A reduction in antioxidant status, enzymatic (catalase, glutathione peroxidase and superoxide dismutase) and non enzymatic (reduced glutathione, non protein thiols and vitamin C) was observed when compared to controls. EVOO supplementation alleviated significantly hematotoxicity induced by acrylamide as evidenced by restoring the biochemical markers cited above to near normal values. Our results revealed that extra virgin olive oil, a main component of olive Mediterranean diet, was effective in preventing erythrocytes damage and oxidative stress.
\end{abstract}

Keywords: Acrylamide, rats, erythrocytes, antioxidant status, Extra virgin olive oil

Pharm Biomed Res 2017; 3(1): 34-40

\section{Introduction}

Acrylamide (ACR) is used in various scientific and industrial processes, such as water treatment, in cosmetics and gel electrophoresis (1). The primary route of ACR exposure for people is through drinking water and food consumption. It is formed in carbohydrate rich foods cooked at high temperatures through interactions of amino acids with reduced sugar (Maillard reaction) (2). ACR forms conjugates with reduced glutathione (GSH). Then the resulting complex is metabolized by cytochrome P450 (CYP 2E1) pathway to form glycidamide (3). The last metabolite is genotoxic leading to the formation of hemoglobin and glycidamide-DNA adducts (4). It accumulates at higher levels in the blood than any other tissues following exposure via oral ingestion, inhalation, or via the dermis (5). Moreover, ACR caused a disruption of hematological parameters, a decrease in erythrocyte membrane resistance and retarded synthesis or destruction of $\mathrm{Hb}$ (6-8). Then, an imbalance between the production of reactive oxygen species (ROS) and antioxidant capacity increased oxidative stress playing a critical role in the toxicity induced by ACR through the lipid peroxidation increase and the impairment of endogenous antioxidant biomarkers (9-11). ROS are produced in erythrocytes by a process known as redox cycling and are catalyzed by transition metals, such as $\mathrm{Fe}^{2+}$ and $\mathrm{Cu}^{2+}(12)$.

Natural dietary antioxidants have been used to protect cells against oxidative damage through scavenging free radicals. Extra Virgin Olive oil (EVOO), one of the most important food products consumed in Mediterranean countries, has been shown to be effective against oxidative stress. EVOO has many applications including cooking, cosmetics, pharmaceutical preparations and soaps. Olive oil, unlike other vegetable oils, contains high amounts of several micronutrient constituents, including polyphenolic compounds such as hydroxytyrosol, tyrosol, and oleuropein (13). It has also been shown to have anti-inflammatory, antithrombotic, antihypertensive and vasodilatory effects in both animals and humans (14). The possible mechanism explaining the beneficial role of EVOO may be due to its contents of monounsaturated fatty acids (MUFA) essentially oleic acid and polyphenols as reported by our previous studies $(15,16)$. Data assessing the health effects of EVOO used as a dietary supplement after acrylamide treatment are lacking. The underlying mechanisms responsible for any 
possible beneficial effect remain to be elucidated. Therefore, we investigated the protective effects of EVOO against ACR-induced hematotoxicity and oxidative stress in erythrocytes.

\section{Materials and methods}

\section{Chemicals}

Acrylamide (ACR), glutathione (oxidized and reduced), nicotinamide adenine dinucleotide phosphate reduced form (NADPH), 5, 5'-dithiobis-2-nitrobenzoic acid (DTNB) and thiobarbituric acid (TBA) were purchased from Sigma (St.Louis; MO, USA). All other chemicals, of analytical grades, were purchased from standard commercial suppliers.

\section{Oil samples analysis}

Biologic Extra virgin olive oil (EVOO) samples were obtained from a Chetoui variety cultivar grown in the North of Tunisia. To verify the quality criteria of olive oil, free acidity, conventionally expressed in oleic acid (g/ $100 \mathrm{~g}$ ), peroxide value (PV) $\left(\mathrm{meqO}_{2} / \mathrm{kg}\right.$ ) and UV absorption characteristics (K232 and K270) were determined according to International Olive Oil Council (17).

\section{Animals and treatment}

Female Wistar rats, weighing $160 \pm 10 \mathrm{~g}$, were obtained from the Central Pharmacy (SIPHAT, Tunisia). They were housed at ambient temperature $\left(22 \pm 2^{\circ} \mathrm{C}\right)$ in a 12-h light/dark cycle and a minimum relative humidity of $40 \%$. Food (SNA, Sfax, Tunisia) and water were available ad libitum. One week after acclimatization to laboratory conditions, the rats were randomly divided into four groups of six each.

Group 1: serving as negative controls where rats received daily by gavage distilled water.

Group 2: rats received daily by gavage Acrylamide (ACR) at a dose of $40 \mathrm{mg} / \mathrm{Kg} \mathrm{BW}$.

Group 3: rats received daily by gavage both ACR and $300 \mu \mathrm{L}$ of EVOO.

Group 4: serving as positive controls where rats received daily by gavage $300 \mu \mathrm{L}$ of EVOO.

The dose of ACR ( $40 \mathrm{mg} / \mathrm{Kg} \mathrm{BW}$ ) caused toxicity without lethality and corresponded to $1 / 8$ of LD50 according to Pan et al., (18). At the end of the experimental period (21 days), all rats were euthanized by cervical decapitation to avoid stress. Approval for rat experiments was obtained from the ethical Committee at Sciences Faculty of Sfax with ethics approval number 1204 and all the experimental procedures were in accordance with the International Guidelines for Animal Care (19).

\section{Blood samples collection}

Some trunk blood samples were collected into EDTA tubes and used either for the determination of hematological parameters
$\left(V_{1}=1 \mathrm{~mL}\right)$ or were centrifuged at $2,200 \times \mathrm{g}$ for $15 \mathrm{~min}\left(\mathrm{~V}_{2}=2 \mathrm{~mL}\right)$ for extraction of erythrocytes according to Sinha et al., (20). Other blood samples $\left(\mathrm{V}_{3}=0.5 \mathrm{~mL}\right)$ were used for determination of osmotic fragility in erythrocytes.

\section{Determination of erythrocytes hemolysis}

Erythrocytes hemolysis was determined by osmotic fragility (OF) using $\mathrm{NaCl}$ solutions at different concentrations according to Hitoshi and Hiroshi (21).

\section{Hematological study}

White (WBCs) and red blood cells (RBCs) counts, hematocrit $(\mathrm{Ht})$, hemoglobin $(\mathrm{Hb})$, mean corpuscular volume (MCV), mean corpuscular $\mathrm{Hb}(\mathrm{MCH})$, and $\mathrm{MCH}$ concentration (MCHC) were analyzed by an electronic automate Coulter MAXM (Beckman Coulter, Inc., Fullerton, CA).

\section{Biochemicals assays}

Protein quantification

Erythrocytes protein contents were measured according to the method of Lowry et al.,(22) using bovine serum albumin as standard.

Assays of oxidative stress and antioxidant defenses in erythrocytes The concentrations of malondialdehyde (MDA), an index of lipid peroxidation were determined according to the method of Draper and Hadley (23). Hydrogen peroxide $\left(\mathrm{H}_{2} \mathrm{O}_{2}\right)$ generation was assessed as described by Ou and Wolff method (24). Protein carbonyl (PCO) content was measured using the DNPH method of Reznick and Packer (25).

The GSH content in erythrocytes was assayed according to the method of Ellman (26) modified by Jollow et al. (27). Non protein thiol (NPSH) levels were determined by the method of Ellman (26). Ascorbic acid level in erythrocytes was performed as described by Jacques-Silva et al. (28). Catalase (CAT), superoxide dismutase (SOD) and glutathione peroxidase (GPx) activities were measured according to the methods of Aebi (29), Beauchamp and Fridovich (30) and Flohe and Gunzler (31) respectively.

\section{Statistical analysis}

The data were analyzed using the statistical package program Stat view 5 Software for Windows (SAS Institute, Berkley, CA). Statistical analysis was performed using one-way analysis of variance (ANOVA) followed by Fisher's protected least significant difference (PLSD) test as a post hoc test for comparison between groups. Student unpaired t-test was also used when comparison between two groups was required. All values were expressed as means $\pm \mathrm{SD}$. The 0.05 level was selected as the point of minimal statistical significance. 


\section{Results}

\section{Quality criteria of olive oil}

The quality criteria of olive oil (acidity, peroxide values and UV specific extinction) were determined. The values of these parameters (Table 1) were included in the ranges established for Extra Virgin Olive Oil (EVOO) category (International Olive Oil Council, 17).

Table 1 Analytical parameters of EVOO (Chetoui variety)

\begin{tabular}{cc}
\hline Analytical parameters & Mean values \\
\hline Free acidity $(\mathrm{g} / 100 \mathrm{~g})$ & 0.41 \\
$\mathrm{~K} 232$ & 2 \\
$\mathrm{~K} 270$ & 0.16 \\
$\mathrm{PV}\left(\mathrm{meqO}_{2} / \mathrm{kg}\right)$ & 7.5 \\
\hline
\end{tabular}

\section{Erythrocytes hemolysis}

We observed an increase in osmotic fragility (OF) of erythrocytes upon ACR treatment reflected by mean erythrocyte fragility (MEF) when compared to control, EVOO and ACR+EVOO groups (Figure 1).

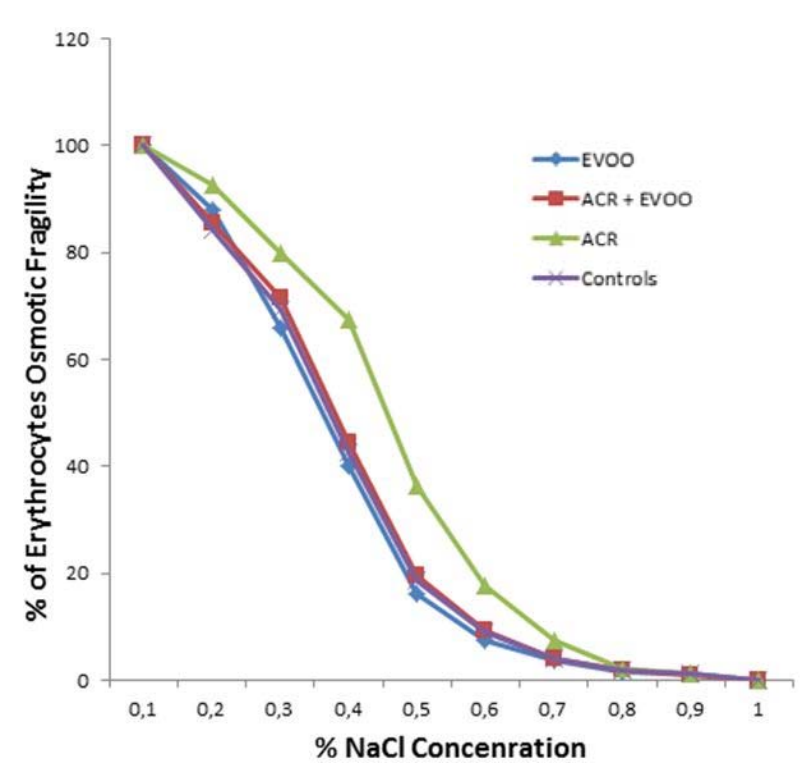

Figure 1 Evolution of erythrocytes osmotic fragility in control and treated rats with $\mathrm{ACR}, \mathrm{EVOO}$ and their combination $(\mathrm{ACR}+\mathrm{EVOO})$ during 21 days.

The number of determinations for each parameter is $n=6$.

\section{Hematological parameters}

Compared with the control group, a decrease in RBC number and $\mathrm{Hb}$ concentration $(\mathrm{p}<0.01$ ) was observed in rats exposed to ACR accompanied with a significant decrease in $\mathrm{Ht}$ percentage $(p<0.001)$ respectively. No significant changes in
$\mathrm{MCV}, \mathrm{MCH}$, and $\mathrm{MCHC}$ values were observed. While, total WBC counts were significantly increased in ACR treated group ( $p<0.001$ ) compared with those of controls (Table 2). The supplementation of EVOO to ACR treated rats ameliorated these hematological parameters. There were no statistical differences of all these parameters between EVOO and control groups (Table 2).

Estimation of $\mathrm{MDA}, \mathrm{H}_{2} \mathrm{O}_{2}, \quad \mathrm{PCO}$ and non enzymatic antioxidant levels in erythrocytes

Our results showed a significant increase in lipid peroxidation, hydrogen peroxide and protein oxidation by 50,69 and $25 \%$ in ACR treated rats when compared to those of controls. When EVOO was administered with ACR, a significant reduction of these biomarkers in the erythrocytes was observed when compared to treated group (Table 3).

GSH, NPSH and vitamin C levels decreased by 18, 31 and $14 \%$, respectively when compared to those of controls. These modifications were significantly improved after coadministration of EVOO without reaching control values (Table 3).

\section{Enzymatic antioxidant status in erythrocytes}

ACR treatment resulted in a significant decrease of CAT (20\%), GPx (-61\%) and SOD (-28\%) activities when compared to those of controls. A significant recovery in these enzymatic antioxidant activities was observed in rats coexposed to ACR and EVOO without reaching control values (Figure 2).

\section{Discussion}

Erythrocytes are vulnerable to oxidative stress due to the high concentrations of polyunsaturated fatty acids, ferrous ions, and molecular oxygen (32). Their membranes are also susceptible to be damaged by ROS-induced peroxidation products like superoxides resulting from $\mathrm{Hb}$ auto-oxidation. In the present study, abnormalities in some blood cell parameters of ACRtreated rats were noted. Thus, we observed a significant decrease in the erythrocytes count, $\mathrm{Ht}$ percentage and $\mathrm{Hb}$ level which indicated the occurrence of microcytic anemia. As reported by Barber et al. (33), acrylamide is electrophilic and able to bind covalently to the cysteine residues forming adducts with sulfhydryl groups on hemoglobin. Consequently, there is a loss of heme by reducing the amount of $\mathrm{Hb}$ in the blood leading to anemic conditions. Additionally, ACR treated rats induced a significant increase in WBC counts, which might indicate the activation of immune system. Administration of EVOO to ACR treated rats induced a 
Table 2 Hematological parameters of control and treated rats with ACR, EVOO and their combination $(\mathrm{ACR}+\mathrm{EVOO})$ during 21 days

\begin{tabular}{ccccc}
\hline $\begin{array}{c}\text { Parameters and } \\
\text { treatments }\end{array}$ & Controls & ACR & ACR+EVOO & EVOO \\
\hline RBC count & $7.91 \pm 0.18$ & $6.61 \pm 0.62^{* *}$ & $7.87 \pm 0.26^{+++}$ & $7.86 \pm 0.25$ \\
$\mathrm{Hb}$ & $13.78 \pm 0.53$ & $12.17 \pm 0.82^{* *}$ & $13.54 \pm 0.51^{++}$ & $13.86 \pm 0.58$ \\
$\mathrm{Ht}$ & $43.3 \pm 1.16$ & $39.95 \pm 0.71^{* * *}$ & $43.26 \pm 1.65^{+++}$ & $42.94 \pm 0.88$ \\
$\mathrm{MCV}$ & $55.12 \pm 0.48$ & $55.75 \pm 1.31$ & $54.62 \pm 0.93$ & $54.04 \pm 0.59$ \\
& & & & \\
$\mathrm{MCH}$ & $17.38 \pm 0.32$ & $17.82 \pm 0.49$ & $17.78 \pm 0.29$ & $17.86 \pm 0.23$ \\
& & & & \\
$\mathrm{MCHC}$ & $32.28 \pm 1.18$ & $32.29 \pm 1.64$ & $33.14 \pm 0.39$ & $33.18 \pm 0.27$ \\
WBC count & $10.65 \pm 0.49$ & $15.33 \pm 0.21^{* * *}$ & $11.32 \pm 0.51^{*+++}$ & $10.56 \pm 0.29$ \\
\hline
\end{tabular}

RBC: Red Blood Cells $\left(10^{6} / \mathrm{mm}^{3}\right)$; Hb: hemoglobin $(\mathrm{g} / \mathrm{dL})$; Ht: Hematocrit $(\%)$; MCV: Mean Corpuscular Volume $\left(\mathrm{mm}^{3} / \mathrm{RBC}\right)$; MCH: Mean Corpuscular Hemoglobin (pg/RBC); MCHC: Mean Corpuscular hemoglobin concentration (g/dL); WBC: White Blood Cells $\left(10^{3} / \mathrm{mm}^{3}\right)$.

Values are means \pm SD for six rats in each group.

ACR; (ACR + EVOO) and EVOO treated groups vs. control group: ${ }^{*} \mathrm{p}<0.05 ;{ }^{*} \mathrm{p}<0.01 ;{ }^{*} * \mathrm{p}<0.001$

$(\mathrm{ACR}+\mathrm{EVOO})$ group vs. ACR group: $++\mathrm{p}<0.01 ;++\mathrm{p}<0.001$.

Table $3 \mathrm{MDA}, \mathrm{H}_{2} \mathrm{O}_{2}$, PCO, GSH, NPSH and vitamin C levels in the erythrocytes of control and treated rats with ACR, EVOO and their combination during 21 days of treatment.

\begin{tabular}{ccccc}
\hline $\begin{array}{c}\text { Parameters \& } \\
\text { treatment }\end{array}$ & Controls & ACR & ACR + EVOO & EVOO \\
\hline $\mathrm{MDA}^{\mathrm{a}}$ & $0.66 \pm 0.03$ & $0.99 \pm 0.05^{* * *}$ & $0.69 \pm 0.04^{+++}$ & $0.65 \pm 0.03$ \\
$\mathrm{H}_{2} \mathrm{O}_{2}{ }^{\mathrm{b}}$ & $0.036 \pm 0.02$ & $0.061 \pm 0.01^{* * *}$ & $0.038 \pm 0.02^{+++}$ & $0.037 \pm 0.01$ \\
$\mathrm{PCO}^{\mathrm{b}}$ & $0.65 \pm 0.02$ & $0.81 \pm 0.05^{* * *}$ & $0.64 \pm 0.03^{+++}$ & $0.66 \pm 0.03$ \\
$\mathrm{GSH}^{\mathrm{c}}$ & $2.63 \pm 0.12$ & $2.18 \pm 0.13^{* * *}$ & $2.65 \pm 0.08^{+++}$ & $2.66 \pm 0.12$ \\
$\mathrm{NPSH}^{\mathrm{b}}$ & $12.33 \pm 1.06$ & $8.53 \pm 0.31^{* * *}$ & $12.18 \pm 0.31^{+++}$ & $12.74 \pm 0.68$ \\
$\mathrm{Vitamin}^{\mathrm{b}}$ & $0.45 \pm 0.04$ & $0.39 \pm 0.02^{* * *}$ & $0.44 \pm 0.04^{+++}$ & $0.46 \pm 0.03$ \\
\hline
\end{tabular}

a: nmoles of MDA/ mg protein, $\mathrm{b}: \mu \mathrm{mol} / \mathrm{mg}$ protein, $\mathrm{c}: \mu \mathrm{g} / \mathrm{mg}$ protein

Values are means \pm SD for six rats in each group.

ACR; (ACR + EVOO) and EVOO treated groups vs. control group: ${ }^{* * *} \mathrm{p}<0.001$.

$(\mathrm{ACR}+\mathrm{EVOO})$ group vs. $(\mathrm{ACR})$ group: $+++\mathrm{p}<0.001$ 

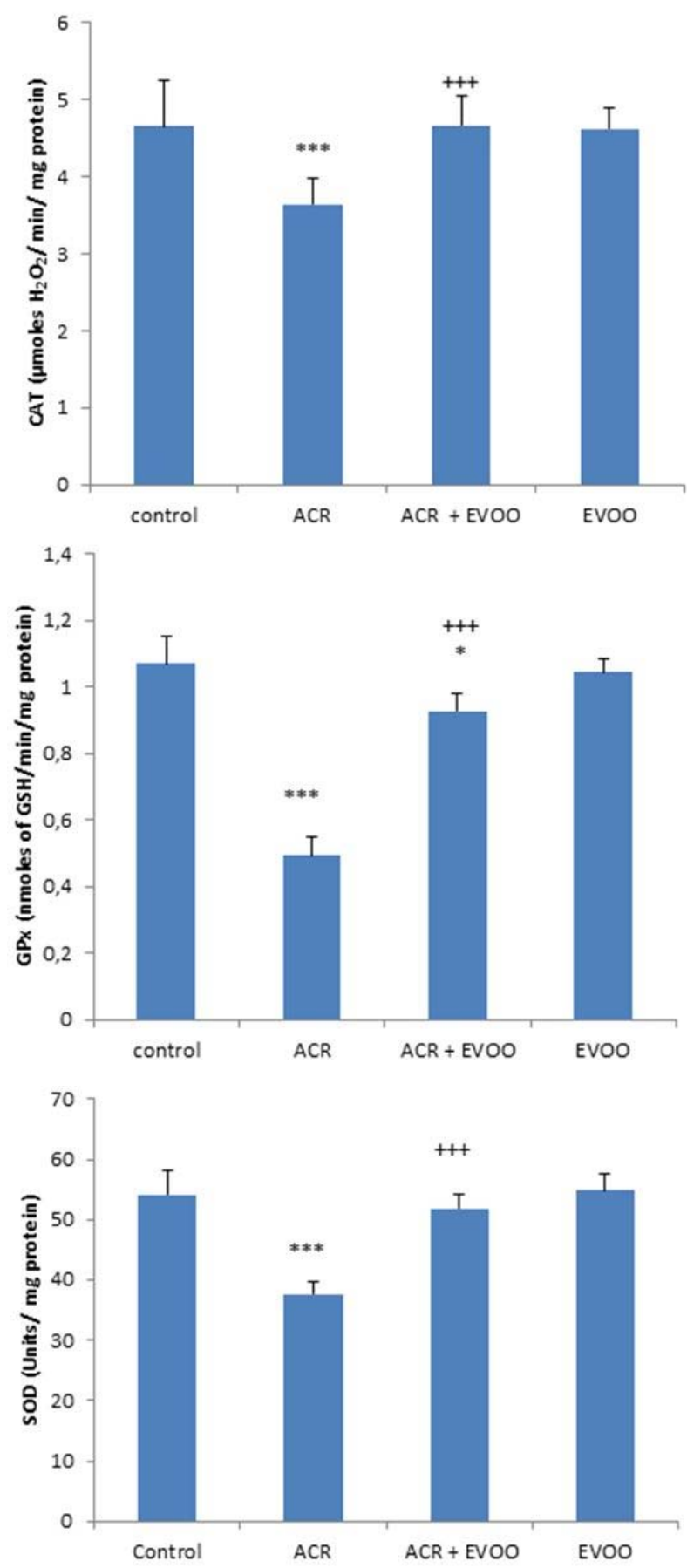

Figure 2 Antioxidant enzyme activities (CAT, GPx and SOD) in the erythrocytes of control and treated rats with ACR, EVOO and their combination (ACR + EVOO) during 21 days.

Values are means \pm SD for six rats in each group.

ACR, (ACR + EVOO) and EVOO treated groups vs. control group:*p $<0.05 ; * * * p<0.001$.

(ACR + EVOO) group vs. ACR group: $+1+p<0.001$.

No statistical differences were observed between EVOO and control groups.

significant recovery of all hematological parameters which could be attributed to the free radical scavenging activity of EVOO.
Normal erythrocyte function is mainly dependent on the integrity of erythrocyte membrane. In fact, osmotic fragility is used to display structural changes of the erythrocytes membrane when they are subjected to osmotic stress. Our results showed an increase of osmotic fragility in ACR treated rats showing the propensity of erythrocytes to hemolysis under osmotic stress. Our results were in accordance with those of Tarskikh (34) who has reported that acute acrylamide toxicity can damage erythrocyte membrane and decrease its hemolytic resistance. The alteration in erythrocyte parameters and intravascular hemolysis of barium treated rats are considered as a consequence of oxidative stress and lipid peroxidation in the circulating erythrocytes (35). Our data showed a significant increase of MDA concentrations as a result of oxidative stress and an excess production of ROS probably generated by ACR. Our results were in agreement with the previous reports of Tarskikh (34) who has demonstrated that MDA level in the erythrocytes of rats increases within $3 \mathrm{~h}$ after acrylate treatment. Furthermore, an overload of ROS is known to modify proteins and to generate PCO products, markers of oxidative injury. ROS, including $\mathrm{H}_{2} \mathrm{O}_{2}$, generated probably by acrylamide treatment induced a rise of protein carbonyls and hydrogen peroxide levels suggesting the dysfunction of the mitochondrial respiration chain. According to Zhao et al., (10), ACR caused changes in oxidative status and mitochondrial function including the excessive ROS generation, function of electron transport chain (ETC) and membrane permeability. Co-treatment with EVOO prevented oxidative damage induced by acrylamide, objectified by a significant decrease in MDA, $\mathrm{H}_{2} \mathrm{O}_{2}$ and PCO levels in erythrocytes. Nakbi et al., (36) have shown that EVOO administered to 2,4-D-treated rats protected erythrocyte membranes against oxidative damage in order to prevent excessive lipid and protein oxidation. According to Teres et al. (37), EVOO increases the levels of oleic acid in cell membranes, which helps to regulate the structure of membrane lipids through control of signalmediated $\mathrm{G}$ protein, causing a reduction in blood pressure.

ROS are continuously produced in erythrocytes due to the high oxygen tension in arterial blood and their abundant iron content (38). The cells have different mechanisms to alleviate oxidative damage including many antioxidant enzymes such as SOD, GPx and CAT.

In our study, the enhanced lipid peroxidation in erythrocytes was accompanied by the decreased activities of CAT, GPx and SOD. The latter enzyme catalyzes the dismutation of superoxide radicals $\left(\mathrm{O}_{2}{ }^{-}\right)$into molecular oxygen $\left(\mathrm{O}_{2}\right)$ and $\mathrm{H}_{2} \mathrm{O}_{2}$. CAT is a hemoprotein which catalyses the reduction of $\mathrm{H}_{2} \mathrm{O}_{2}$ to water and oxygen and thus protects the cells from 
oxidative damage by $\mathrm{H}_{2} \mathrm{O}_{2}$ and $\mathrm{OH}$. The decrease of these enzymes is probably due to an enhanced production of superoxide radicals (39) or down-regulation in the synthesis of antioxidant enzymes by persistent toxic insult (40). When oxidative stress is in excess, the non-enzymatic antioxidant status like glutathione (GSH), non-protein thiols (NPSH) and vitamin $\mathrm{C}$ complements the activity of the enzymatic antioxidant system. In our study, these antioxidants were greatly decreased in the erythrocytes of ACR-treated rats reflecting their consumption through oxidative stress. Because GSH is involved in recycling vitamin $\mathrm{C}$ by mediating the reduction of dehydroascorbate (41), the GSH deficiency would be expected to reduce the vitamin $\mathrm{C}$ levels in treated rats. As has been previously reported by us, exposure of rats to acrylamide at a dose of $20 \mathrm{mg} / \mathrm{Kg}$ BW induces lipid peroxidation as well as a reduction of the antioxidant system in erythrocytes (42). EVOO administration improved significantly the levels of antioxidant status in erythrocytes to near normal values through SH groups protection and by scavenging free radicals. Our results were in agreement with O'Dowd (43) and Sarria et al. (44) who have reported that olive oil phenolic compounds are the effective scavengers of hydroxyl, superoxide, and peroxyl radicals.

\section{References}

1. Parzefall W. Minireview on the toxicity of dietary acrylamide. Food Chem Toxicol 2008;46:1360-4.

2. Tareke E, Rydberg P, Karlsson P, Eriksson S, Tomqvist M. Analysis of acrylamide, a carcinogen formed in heated foodstuffs. J Agric Food Chem 2002;50:4998-5006.

3. Lee JG, Wang YS, Chou CC. Acrylamide-induced apoptosis in rat primary astrocytes and human astrocytoma cell lines. Toxicol In Vitro 2014;28:562-70.

4. Ghanayem BI, McDaniel LP, Churchwell MI, Twaddle NC, Snyder R, Fennell $\mathrm{TR}$, et al. Role of CYP2E1 in the epoxidation of acrylamide to glycidamide and formation ofDNA and hemoglobin adducts. Toxicol Sci 2005;88:311-8.

5. Shipp A, Lawrence G, Gentry R, McDonald T, Bartow H, Bounds J, et al. Acrylamide: review of toxicity data and dose- response analyses for cancer and non cancer effects. Crit Rev Toxicol 2006; 36:481-608.

6. Arihan O, Seringec NB, Gurel EI, Dikmenoglu NH. Effects of oral acrylamide intake on blood viscosity parameters in rats. Clin Hemorheol Microcirc 2011;47:45-52

7. Rawi SM, Marie SM, Sohair R. Fahmy SR, El-Abied SA. Hazardous effects of acrylamide on immature male and female rats. Afr J Pharm and Pharmacol 2012;6:1367-86.

8. Ali MA, Aly EM, Elawady AI. Effectiveness of selenium on acrylamide toxicity to retina. Int JOphthalmol 2014; 7:614-20.

9. Abdel-Daim MM, Abd Eldaim MA,Hassan AG. Trigonella foenum-graecum ameliorates acrylamide-induced toxicity in rats: Roles of oxidative stress, proinflammatory cytokines, and DNA damage. Biochem Cell Biol 2015;93:1928.

10. Zhao M, Wang P, Zhu Y, Liu X, Hu X, Chen F. The chemoprotection of a blueberry anthocyanin extract against the acrylamide-induced oxidative stress in mitochondria: unequivocal evidence in mice liver. Food Funct 2015;6:3006-12.

11. Aydin B. Effects of argan oil on the mitochondrial function, antioxidant system and the activity of NADPH- generating enzymes in acrylamide treated rat brain. Biomed Pharmacother 2017;87:476-81.

\section{Conclusion}

The underlying mechanism of acrylamide induced hematotoxicity may be related to the excess generation of reactive oxygen species leading to oxidative stress. Coadministration of EVOO alleviated significantly hematological parameters, lipid and protein oxidation and the reduction of antioxidant status in erythrocytes. These beneficial effects of EVOO are mediated probably via its anti-oxidant power and the free radical scavenging activities of monounsaturated fatty acids, carotenoids, tocopherols, and polyphenols.

\section{Acknowledgements}

This work was supported by the Ministry of Higher Education and Scientific Research in Tunisia (DGRST grants, LR 11/ ES-53 Sciences Faculty of Sfax). The authors are indebted to Mr Menaa Assili and Mr Chedli Tmar for their skilful technical assistance.

\section{Conflit of interest}

The authors declare that they have no competing interests to disclose.

12. Dhan P, Brahma NS, Garima U. Antioxidant and free radical scavenging activities of phenols from onion (Allium cepa). Food Chem 2007;102:1389-93.

13. Sirtori CR, Gatti E, Tremoli E, Galli C, Gianfranceschi G, Franceschini $\mathrm{G}$, et al. Olive oil, corn oil, and n-3 fatty acids differently affect lipids, lipoproteins, platelets, and Superoxide formation in type II hypercholesterolemia. Am J Clin Nutr 1992;56:113-22.

14. Covas MI. Olive oil and cardiovascular system. Pharmacol Res 2007; 55:175-86.

15. Ghorbel I, Chaâbane M, Boudawara O, Kamoun NG, Boudawara T, Zeghal N. Dietary unsaponifiable fraction of extra virgin olive oil supplementation attenuates lung injury and DNA damage of rats coexposed to aluminum and acrylamide. Environ Sci Pollut Res Int 2016; 23:19397-408.

16. Ghorbel I, Elwej A, Fendri N, Mnif H, Jamoussi K, Boudawara T, et al. Olive oil abrogates acrylamide induced nephrotoxicity by modulating biochemical and histological changes in rats. Ren Fail 2017;39:236-45.

17. International Olive Oil Council (IOOC). Trade Standard Applying to Olive Oils and Olive-pomace Oils; 2008.

18. Pan X, Zhu L, Lu H, Wang D, Lu Q, Yan H. Melatonin attenuates oxidative damage induced by acrylamide in vitro and In vivo. Oxid Med Cell Longev 2015;2015:1-12.

19. Maryland RC. Guide for the care and use of laboratory animals. Institute of laboratory animal resources commission on life Sciences. National Research Council, National Academies Press, Washington DC, 1996.

20. Sinha M, Manna P, Sil PC. A $43 \mathrm{kD}$ protein from the herb, Cajanus indicus $\mathrm{L}$, protects against fluoride induced oxidative stress in mice erythrocytes.Pathophysiology 2007;14:47-54.

21. Mineo H, Hara H. Structure-dependent and receptor-independent increase in osmotic fragility of rat erythrocytes by short-chain fatty acids. Biochim Biophys Acta 2005;1713:113-7.

22. Lowry OH, Rosebrough NJ, Farr AL, Randall R J. Protein measuremernt with the Folin phenol reagent. J Biol Chem 1951;193:265-75.

23. Draper HH, Hadley M. Malondialdehyde determination as index of lipid peroxidation. Methods Enzymol 1990;186:421-31.

24. Ou P, Wolff SP. A discontinuous method for catalase determination at 
near physiological concentrations of $\mathrm{H}_{2} \mathrm{O}_{2}$ and its application to the study of $\mathrm{H}_{2} \mathrm{O}_{2}$ fluxes within cells. J Biochem Biophys Methods 1996;31:59-67.

25. Reznick Z, Packer L. Oxidative damage to proteins: spectrophotometric method for carbonyl. Method Enzymol 1994; 233:357-63.

26. Ellman GL. Tissue sulfhydryl groups. Arch Biochem Biophys 1959;82: 70-7.

27. Jollow DJ, Mitchell JR, Zampaglione N, Gillette JR. Bromobenzeneinduced liver necrosis. Protective role of glutathione and evidence for 3, 4 bromobenzene oxide as the hepatotoxic metabolite. Pharmacol 1974;11:151-69.

28. Jacques-Silva MC, Nogueira CW, Broch LC. Diphenyl diselenide and ascorbic acid changes deposition of selenium and ascorbic acid in liver and brain of mice. Pharm Toxicol 2001;88:119-25.

29. Aebi H. Catalase in vitro. Methods Enzymol 1984;105:121-6.

30. Beauchamp C, Fridovich I. Superoxide dismutase: improved assays and an assay applicable to acrylamide gels. Anal Biochem 1971;44:276-87.

31. Flohe L, Gunzler WA. Assays of glutathione peroxidase. Methods Enzymol 1984;108:114-21.

32. Yadav P, Sarkar S and Bhatnagar D. Lipid peroxidation and antioxidant enzymes in erythrocytes and tissues in aged diabetic rats. Indian J Exp Biol 1997;35: 389-92.

33. Barber DS, Hunt JR, Ehrich MF, Lehning EJ, LoPachin RM. Metabolism, toxicokinetics and hemoglobin adduct formation in rats following subacute and subchronic acrylamide dosing. Neuro Toxicol 2001;22:341-53.

34. Tarskikh MM. Damage to erythrocyte membranes as the mechanism for acrylate toxicity. Bull Exp Biol Med 2006;142:690-2.

35. Elwej A, Ben Salah G, Kallel C, Fakhfakh F, Zeghal N, Ben Amara I Protective effects of pomegranate peel against hematotoxicity, chromosomal aberrations, and genotoxicity induced by barium chloride in adult rats.Pharm Biol 2016;54:964-74.

36. Nakbi A, Tayeb W, Dabbou S, Issaoui M, Grissa AK, Attia N, Hammami M.Dietary olive oil effect on antioxidant status and fatty acidprofile in the erythrocyte of 2,4-D- exposed rats. Lipids Health Dis 2010;9:89.

37. Teres S, Barcelo-Coblijn G, Benet M, Alvarez RA, Bressani R, Halver JE Oleic acid content is responsible for the reduction in blood pressure induced by olive oil. Proc Natl Acad Sci 2008;105:13811-6.

38. Pandey KB, Rizvi SI. Biomarkers of oxidative stress in red blood cells. Biomed Pap 2011; 155:131-6.

39. Yamanaka K, Hasegawa A, Sawamura R, Okada S. Cellular response to oxidative damage in lung induced by the administration of dimethy larsinic acid, a major metabolite of inorganic arsenics, in mice. Toxicol Appl Pharmacol 1991;108:205-13.

40. Irshad M, Chaudhuri PS. Oxidant-antioxidant system: role and significance in human body. Ind J Exp Biol 2002;40:1233-9.

41. Rivers JM. Safety of high-level vitamin C ingestion. Int J Vitam Nutr Res Suppl. 1989;30:95-102.

42. Ghorbel I, Maktouf S, Kallel C, Ellouze Chaabouni S, Boudawara T, Zeghal N. Disruption of erythrocyte antioxidant defense system, hematological parameters, induction of pro-inflammatory cytokines and DNA damage in liver of co-exposed rats to aluminium and acrylamide. Chem Biol Interact 2015; 236:31-40.

43. O'Dowd Y, Driss F, Dang PM, Elbim C, Gougerot-Pocidalo MA, Pasquier C, et al. Antioxidant effect of hydroxytyrosol, a polyphenol from olive oil: scavenging of hydrogen peroxide but not superoxide anion produced by human neutrophils. Biochem Pharmacol 2004;68:2003-8.

44. Sarria B, Mateos R, Gallardo E, Ramos S, Martín MA, Bravo L, et al. Nitro derivatives of olive oil phenols protect $\mathrm{HepG} 2$ cells against oxidative stress. Food Chem Toxicol 2012;50:3752-8. 